\title{
Cannabinoid Withdrawal Produces Altered Somatic and Emotionality-related Behavior in Mice
}

\author{
Kristen R. Trexler
}

Follow this and additional works at: https://researchrepository.wvu.edu/etd

\section{Recommended Citation}

Trexler, Kristen R., "Cannabinoid Withdrawal Produces Altered Somatic and Emotionality-related Behavior in Mice" (2017). Graduate Theses, Dissertations, and Problem Reports. 6830.

https://researchrepository.wvu.edu/etd/6830

This Thesis is protected by copyright and/or related rights. It has been brought to you by the The Research Repository @ WVU with permission from the rights-holder(s). You are free to use this Thesis in any way that is permitted by the copyright and related rights legislation that applies to your use. For other uses you must obtain permission from the rights-holder(s) directly, unless additional rights are indicated by a Creative Commons license in the record and/ or on the work itself. This Thesis has been accepted for inclusion in WVU Graduate Theses, Dissertations, and Problem Reports collection by an authorized administrator of The Research Repository @ WVU. For more information, please contact researchrepository@mail.wvu.edu. 


\title{
Cannabinoid withdrawal produces altered somatic and emotionality-related behavior in mice
}

\author{
Kristen R. Trexler \\ Thesis submitted \\ to the Eberly College of Arts and Sciences \\ at West Virginia University \\ in partial fulfillment of the requirements for the degree of \\ Master of Science in Psychology \\ Steven G. Kinsey, Ph.D., Chair \\ Karen G. Anderson, Ph.D. \\ Amy Fiske, Ph.D. \\ Department of Psychology \\ Morgantown, West Virginia \\ 2016
}

Key words: Cannabinoid, cannabis, drug abuse, anxiety and depression, withdrawal, mice

Copyright 2016 Kristen R. Trexler 


\begin{abstract}
Cannabinoid withdrawal produces altered somatic and emotionality-related behavior in mice
\end{abstract}

Kristen R. Trexler

Cannabis sativa is the most commonly abused illicit drug in the United States. An estimated 9 percent of those who use cannabis will develop some level of cannabinoid use disorder (CUD). Although behavioral therapy has some success in treating CUD, many users still relapse. Moreover, there are no FDA approved pharmacological treatments available to complement behavioral therapy. The need for appropriate treatments highlights the need for nonhuman animal models to test target compounds. The current study aimed to (1) evaluate the MAGL inhibitor JZL184 as a possible treatment for cannabinoid withdrawal, and (2) to develop a spontaneous model of cannabinoid withdrawal in mice. Mice were treated with the primary psychoactive component of cannabis, $\Delta^{9}$-tetrahydrocannabinol (THC; $50 \mathrm{mg} / \mathrm{kg}$ ) or vehicle for 5.5 days. On the $6^{\text {th }}$ day, withdrawal was precipitated using the cannabinoid receptor antagonist rimonabant ( $3 \mathrm{mg} / \mathrm{kg}$ ), and behavior was scored in marble burying and somatic signs tests. THC withdrawal significantly decreased marble burying, however, JZL184 pretreatment did not attenuate withdrawal-related changes marble burying. JZL184 attenuated withdrawal-induced somatic behaviors as demonstrated in previous studies. A second set of experiments was used to evaluate spontaneous (i.e., not precipitated) THC withdrawal, as measured through marble burying and somatic signs. THC withdrawal caused significant increases in paw tremors and head twitches 24-48 h after abstinence, and JZL184 significantly attenuated these somatic signs of withdrawal. These data support the use of endocannabinoid manipulation to reduce symptoms of THC withdrawal. 


\section{ACKNOWLEDGEMENTS}

I would like to thank my lab mates, Molly Crowe and Sara Nass, my undergraduate lab assistant, Austin McKitrick, and Selena Engebretson for technical assistance. This project was supported by The National Institutes of Health [DA038714] and the National Institute of General Medicinal Sciences T32 [GM081741]. 


\section{TABLE OF CONTENTS}

Introduction 1

Cannabinoids 2

Cannabis Withdrawal $\quad 5$

Rodent models of withdrawal 6

$\begin{array}{ll}\text { Methods } & 7\end{array}$

$\begin{array}{ll}\text { Animals } & 7\end{array}$

Drugs $\quad 8$

$\begin{array}{ll}\text { Withdrawal paradigm } & 8\end{array}$

$\begin{array}{ll}\text { Experimental design } & 10\end{array}$

$\begin{array}{ll}\text { Statistical analyses } & 12\end{array}$

Results 13

Experiment 1.1: Establish rimonabant-precipitated withdrawal: somatic signs model 13

Experiment 1.2a: Attenuate withdrawal with a MAGL inhibitor in somatic signs 13 Experiment 1.2b: Attenuate withdrawal with a MAGL inhibitor in $\begin{array}{ll}\text { marble burying } & 13\end{array}$

Experiment 2.1: Spontaneous withdrawal in marble burying 14 Experiment 2.2: Spontaneous withdrawal in somatic signs 15

$\begin{array}{ll}\text { Discussion } & 15\end{array}$

$\begin{array}{ll}\text { Limitations } & 17\end{array}$

$\begin{array}{ll}\text { Future directions } & 18\end{array}$

$\begin{array}{lr}\text { Conclusion } & 18\end{array}$

$\begin{array}{ll}\text { References } & 20\end{array}$

$\begin{array}{ll}\text { Tables } & 26\end{array}$

$\begin{array}{ll}\text { Figures } & 27\end{array}$ 


\section{NONSTANDARD ABBREVIATIONS}

2-AG: 2-arachidonolyglycerol

CB: Cannabinoid

$\mathrm{CB}_{1}$ : Cannabinoid receptor subtype 1

$\mathrm{CB}_{2}$ : Cannabinoid receptor subtype 2

FAAH: Fatty acid amide hydrolase

JZL184: A selective MAGL inhibitor that indirectly raises 2-AG levels

MAGL: Monoacylglycerol lipase

Rimonabant: SR141716A; a selective $\mathrm{CB}_{1}$ receptor antagonist

THC: $\Delta^{9}$-tetrahydrocannabinol

Veh: Vehicle (1:1:18 parts of ethanol, Cremophor, and saline) 


\section{Introduction}

Drug abuse is a maladaptive use of a substance leading to clinically relevant deficiency or distress (American Psychiatric Association, 2013). The abuse of psychoactive substances can lead to addiction or dependence, which is characterized by compulsive drug seeking and use despite negative consequences that may be associated with use (NIDA, 2014). When an addicted individual attempts cessation or reduction of drug use, they may experience withdrawal. Withdrawal is defined as a group of symptoms, varying in severity, which are experienced after cessation or reduction in the use of a psychoactive substance that has been taken repeatedly (American Psychiatric Association, 2000). For example, individuals experiencing withdrawal from cannabis often report symptoms including sleep disturbances, changes in appetite, depression, anxiety, nausea, and increased irritability (American Psychiatric Association, 2013). These abstinence-induced disturbances have recently been described as a continuum of cannabis use disorder (CUD). Current estimates suggest that approximately 6-9\% of cannabis users will develop some degree of CUD (Piomelli, Haney, Budney, \& Piazza, 2016). The negative side effects of withdrawal often lead to relapse after attempted cessation.

Along with behavior modification, adjuvant therapies are often used to reduce the incidence of relapse. A classic example of such an adjuvant approach is the substitution of methadone for heroin dependence. With the recent policy changes legalizing cannabis in many states, misuse and dependence will likely also increase. However, there are no adjuvant therapies currently available for cannabis dependence. The purpose of the proposed study is to develop new experimental animal models of cannabinoid dependence that more closely relate to withdrawal in humans, with the ultimate goal of informing cannabis withdrawal therapeutic interventions. 


\section{Cannabinoids}

Cannabinoids are molecules that (1) bind to and activate the cannabinoid (CB) receptors, or (2) share structural homology with known CB receptor ligands (Mechoulam \& Parker, 2012). These receptor ligands can either activate (agonism) or inactivate (antagonism) the receptor system. The cannabinoid receptor system is comprised of two G-protein coupled receptors, Cannabinoid receptor subtype 1 (i.e., $\mathrm{CB}_{1}$ ) and Cannabinoid receptor subtype 2 (i.e., $\mathrm{CB}_{2}$ ). The $\mathrm{CB}_{1}$ receptor is widely expressed throughout the brain, with the highest concentration in the cerebellum (Regard, Sato, \& Coughlin, 2009). CB 1 agonism is associated with the mild euphoria, relaxation, motor function disruption, and analgesia typically reported during cannabis use. On the other hand, $\mathrm{CB}_{2}$ is more prevalent in the peripheral tissues and the brainstem and largely functions to inhibit inflammation in immune cells. $\mathrm{CB}_{2}$ has been implicated in anti-inflammatory and immunosuppressive effects as well as analgesia, which is a decrease in pain response (Lombard, Nagarkatti, \& Nagarkatti, 2007). These anti-inflammatory properties of $\mathrm{CB}_{2}$ activation have prompted the exploration of cannabinoids as treatments for a multitude of conditions including AIDS-related anorexia and cancer-related vomiting (Pertwee, 2009).

Both exogenous (i.e., externally administered) and endogenous (i.e., internally produced) cannabinoids bind to $\mathrm{CB}_{1}$ and $\mathrm{CB}_{2}$ receptors with moderate to high affinity (Lombard et al., 2007; Singh et al., 2012). In addition to many agonists of the CB receptors, several compounds have been synthesized that selectively antagonize either $\mathrm{CB}_{1}$ or $\mathrm{CB}_{2}$. For example, some $\mathrm{CB}_{1}$ antagonists are rimonabant (SR141716), AM251, AM281, whereas the best characterized CB 2 antagonists include SR144528 and AM630. Cannabinoids can be broken down and categorized based on their origin into three classes: phytocannabinoids, endogenous cannabinoids (i.e., endocannabinoids) and synthetic cannabinoids. 


\section{Phytocannabinoids}

Phytocannabinoids are derived from the Cannabis plant and include $\Delta^{9}$ -

tetrahydrocannabinol (THC) and cannabidiol, among many others (Fisar, 2009). So far, over 60 different cannabinoids have been identified in cannabis, however, THC is the main psychoactive component (Gaoni \& Mechoulam, 1964). In addition to mild euphoria, THC causes cognitive changes, such as memory loss and altered time perception. These side effects can be attenuated in some circumstances by administration of the cannabinoid cannabidiol (Mechoulam \& Parker, 2012; Morgan, Schafer, Freeman, \& Curran, 2010). The ratio of cannabidiol to THC within a cannabis strain largely determines the severity of memory loss associated with cannabis use (Mechoulam \& Parker, 2012). Cannabidiol has also received much recent attention as an antiepileptic drug, and many parents have administered various cannabis extracts to their children, despite sparse empirical evidence.

\section{Endocannabinoids}

Endocannabinoids are produced endogenously in humans and other animals (Fisar, 2009). The two recognized endocannabinoids are anandamide and 2-arachidonylglycerol (i.e., 2AG) (Mechoulam \& Parker, 2012). Both anandamide and 2-AG bind to either $\mathrm{CB}_{1}$ or $\mathrm{CB}_{2}$ and are locally synthesized in neurons as needed (Brents, Zimmerman, Saffell, Prather, \& Fantegrossi, 2013). The endocannabinoids are metabolized by enzymes that tightly regulate brain levels of either endocannabinoid. Anandamide is broken down by the enzyme fatty acid amide hydrolase (FAAH), whereas 2-AG is primarily broken down by the enzyme monoacylglycerol lipase (MAGL, Figure 1), although a small fraction is catabolized by the enzymes ABHD6 and ABHD12 (Blankman, Simon, \& Cravatt, 2007). These enzymes are extremely efficient and render the exogenous administration of endocannabinoids useless. Thus, in order to study effects 
of endocannabinoids in vivo, several compounds have been synthesized that act to selectively inhibit the activity of these catabolic enzymes, thereby indirectly increasing brain levels of anandamide or 2-AG. For example, some FAAH inhibitors include URB597, PF-3845, and URB937, whereas MAGL inhibitors include JZL184 and KML29.

\section{Synthetic cannabinoids}

The third category of cannabinoids is comprised of laboratory-produced compounds that bind to either CB receptor with varying affinity. These compounds were originally developed for research purposes, such as receptor/ligand interaction studies, or to selectively agonize $\mathrm{CB}_{2}$ without also agonizing $\mathrm{CB}_{1}$, with the goal of developing anti-inflammatory drugs.

Shortly following the publication of the structures of synthetic compounds, synthetic cannabinoids entered the mainstream as a new class of drugs of abuse, commonly branded as "K2" or "Spice.” Creating these substances involves the manual addition of a solvent containing synthetic cannabinoid(s) to dried plant material. K2 and Spice are both sold as “incense,” labeled "not for human consumption" and are not regulated by the FDA, all of which makes dosing unpredictable (Brents et al., 2013). In humans, synthetic cannabinoids have many negative consequences associated with them including tachycardia, hypertension, nausea, vomiting, convulsions, agitation, hallucinations, and psychosis, with more serious consequences including respiratory depression and kidney failure (Every-Palmer, 2011; Hermanns-Clausen, Kneisel, Szabo, \& Auwärter, 2013; McQuade, Hudson, Dargan, \& Wood, 2013). The cause of these adverse effects, which are not typically observed with phytocannabinoid use, is not fully understood. However, one likely cause is the higher affinity with which the synthetic cannabinoids bind to cannabinoid receptors, as compared to phytocannabinoids (Atwood, Lee, Straiker, Widlanski, \& Mackie, 2011; Rajasekaran, Brents, Franks, Moran, \& Prather, 2013). 
Like other cannabinoids, there is a risk of dependence and withdrawal liability associated with chronic synthetic cannabinoid use (Van Hout \& Hearne, 2016; Zimmermann et al., 2009), although little work has been published on synthetic cannabinoid dependence.

Cannabis Withdrawal

In the United States, cannabis sativa is the most widely used illicit drug, accounting for 80.6\% of all illicit drug use (Center for Behavioral Health Statistics and Quality, 2015).Within the last decade, the estimated incidence of daily users of cannabis has risen from 5 million to 8 million individuals (Center for Behavioral Health Statistics and Quality, 2015). Moreover, as strains of cannabis have been manipulated, high potency strains of cannabis have become both more readily available and more popular among users (Chait \& Burke, 1994). Perhaps not surprisingly, an increase in cannabis potency (i.e., increased THC concentration) may increase the incidence for dependence (Cooper \& Haney, 2009; Freeman \& Winstock, 2015).

In addition to the social implications of drug dependence, cannabis dependence is problematic because it can contribute to long-term health problems, such as cognitive deficits and psychiatric, cardiovascular and respiratory disorders (Allsop, Lintzeris, Copeland, Dunlop, \& McGregor, 2015). It is estimated that between 5 and 9\% of cannabis users will develop dependence (Anthony, Warner, \& Kessler, 1994), defined by the DSM-5 as Cannabis Use Disorder. Further, as much as $25 \%$ of those seeking substance-abuse treatment are dependent on cannabis (Ramesh \& Haney, 2015).

With regard to treatment, several psychosocial treatment models are in use including cognitive-behavioral therapy, motivational-enhancement therapy, contingency management, and family-based therapies, all of which have seen only modest success rates (Sherman \& McRaeClark, 2016). Approximately 70\% of individuals treated with psychosocial therapies relapse into 
cannabis use (Ramesh \& Haney, 2015). Relapse often occurs in an attempt to attenuate symptoms of withdrawal, which can include: anger, anxiety, depressed mood, sleep disturbances, irritability, and decreased appetite (Aceto, Scates, Lowe, \& Martin, 1995; Ramesh \& Haney, 2015). Whereas other dependence-inducing drugs have agonists that are substituted as a possible pharmacological treatment, there are currently no suitable agonist treatments for cannabis dependence (Allsop et al., 2015). This lack of effective treatment highlights the need for novel treatment options which, in turn, creates a need for appropriate models of dependence and withdrawal in animals.

Rodent models of withdrawal

Dependence and withdrawal can be induced in non-human animals, thereby allowing for experimental research in the area of drug abuse. Models often quantify visible characteristics that are specifically observed during withdrawal. For example, the somatic signs frequently observed following cannabinoid withdrawal are paw tremors (i.e., a clapping motion of the forepaws) and head twitches (i.e., quick rotation of the head from side to side) (Aceto, Scates, \& Martin, 2001; Lichtman, Fisher, \& Martin, 2001; Schlosburg et al., 2009). Although these are reliable measures, their external validity has been criticized, because humans do not exhibit these behaviors during withdrawal. Moreover, somatic models do not measure the primary symptoms of cannabinoid withdrawal in humans, such as affective changes. Thus, one goal of the proposed study is to investigate the affective-like effects of THC withdrawal in mice.

\section{Emotionality measures}

One measure of emotionality in preclinical, animal models is the marble burying task. In this test, animals are placed into a Plexiglas test chamber with approximately $5 \mathrm{~cm}$ of loose bedding. Marbles are laid out evenly in a grid pattern across the bedding and the animal is 
allowed to explore the cage for a fixed amount of time. At the end of the test, the number of marbles buried is recorded. Marble burying has been used as a measure of emotionality in mice, because it is sensitive to effects of anxiolytics; when anxiolytics are administered prior to testing, fewer marbles are buried (Kinsey, O'Neal, Long, Cravatt, \& Lichtman, 2011; Thomas et al., 2009). Similarly, marble burying is sensitive to inhibition of either FAAH or MAGL, indicating that endocannabinoid activity alters this measure of emotionality (Kinsey et al., 2011). Unpublished data from the Kinsey lab indicate that rimonabant-precipitated THC withdrawal causes a significant decrease in marble burying (Trexler et al., in preparation). Although rimonabant per se does not affect marble burying, it is unknown whether this test of emotionality is affected by spontaneous THC withdrawal.

The purpose of the present study was two-fold. First, I hypothesized that the MAGL inhibitor JZL184 would reverse precipitated THC withdrawal-induced changes in marble burying and somatic behaviors (e.g., paw tremors and head twitches). The second goal was to develop a spontaneous (i.e., not precipitated) THC withdrawal model. I hypothesized that abstinence from THC would significantly alter marble burying and somatic signs within $48 \mathrm{~h}$ of drug cessation. In addition, I also administered JZL184 to test the hypothesis that MAGL inhibition attenuates spontaneous THC withdrawal behaviors.

\section{Methods}

Animals

A total of 170 adult male C57BL/6J mice (Jackson Laboratories; Bar Harbor, ME) were used in this study. Treatment groups are detailed in the Table. Mice were group housed (4-5 per cage) in Polysulfone plastic cages with food and water available ad libitum. Mice were housed in a temperature $\left(20-22^{\circ} \mathrm{C}\right)$ and humidity $(50 \pm 5 \%)$ controlled room in the Life Sciences Building 
vivarium. Mice were kept on a 12:12 h light/dark cycle and were randomly assigned to each treatment group. The Animal Care and Use Committee at West Virginia University approved all of the experimental protocols (14-1007).

Drugs

$\Delta^{9}$-tetrahydrocannabinol (THC) and rimonabant (SR141716A) were provided by the National Institute on Drug Abuse Drug Supply Program (Bethesda, MD). JZL184 was purchased from Cayman Chemical (Ann Arbor, MI). All drugs were dissolved in a vehicle mixture of ethanol, Cremophor (Sigma-Aldrich, St. Louis, MO), and saline in a ratio of 1:1:18 parts (Kinsey \& Cole, 2013). All solutions were warmed to room temperature before injection at a volume of $10 \mu \mathrm{l} / \mathrm{g}$ body mass.

\section{Withdrawal paradigm}

Precipitated withdrawal: Mice ( $\mathrm{n}=48$; See Table) were weighed daily and injected subcutaneously (s.c.) with either THC (50 mg/kg) or vehicle every $12 \mathrm{~h}$ for 5.5 days (Falenski et al., 2010; Schlosburg et al., 2009). On the sixth day, all mice received an injection of THC or vehicle (according to their randomly assigned group). Approximately 30 min after the THC or vehicle injection, mice received an intraperitoneal (i.p.) injection of rimonabant (3 mg/kg) to precipitate withdrawal (see Fig. 2). Mice were assessed in one of the behavioral tests detailed below by an experimenter who was blinded to treatment conditions. The precipitated model described was used for Experiment 1.1, 1.2a and 1.2b.

Spontaneous withdrawal: Mice ( $\mathrm{n}=132$; See Table) were weighed daily and injected subcutaneously (s.c.) with either THC (50 mg/kg) or vehicle every $12 \mathrm{~h}$ for 5.5 days (Schlosburg et al., 2009). On the sixth day, all mice received an injection of THC or vehicle (according to their randomly assigned group). Mice tested at 12 and $36 \mathrm{~h}$ post-injection had injection schedules 
offset by $12 \mathrm{~h}$ to allow for testing during the light period of the 12:12 h light/dark cycle (lights on at 6:00 AM). Behavioral assessments were conducted following the THC or vehicle injection and were repeated one or more times. Mice were assessed in one of the behavioral tests detailed below by an experimenter who was blinded to treatment conditions. The spontaneous model described was used for Experiment 2.1 and 2.2.

Somatic signs testing: Somatic signs were measured by placing the mice into empty plastic boxes (20 cm x $20 \mathrm{~cm}$ x $15 \mathrm{~cm}$ ) inside sound-attenuating chambers. The boxes had three clear sides and one mirrored side that faced a camera to allow for observation of behavior when the mice were not facing the camera. Each box was illuminated by an LED array to allow for accurate coding of video following the test.

In testing precipitated withdrawal, the mice were habituated to the test apparatus for 30 min and were then removed and injected with THC or vehicle, as previously described (Schlosburg et al., 2009). While the mice were removed, the boxes were wiped out using a paper towel moistened with distilled water, to remove any waste. The mice were then placed back into the boxes and recorded for $60 \mathrm{~min}$. Mice used to evaluate spontaneous withdrawal were not habituated to the boxes because they were tested repeatedly and, thus, testing began immediately following injection. Video of the mice was recorded by a camera mounted on the back wall of each box. Video for each test was hand scored by a blinded, trained observer. A subset of nine videos was scored by a second trained observer to ensure inter-rater reliability $(\mathrm{r}=.94)$.The dependent variables were (1) number of paw tremors and (2) number of head twitches. Behaviors were scored for incidences, rather than a separate score for each behavior (i.e. an incidence was scored for 'paw tremor' when the behavior was observed, not for each individual motion). Incidences were considered separate when either (1) another behavior occurred between the 
incidences or (2) when there was a time span of at least $1 \mathrm{~s}$ between incidences (Schlosburg et al., 2009).

Marble burying test: Marble burying was measured by placing the mice into plastic test chambers (30 cm x $40 \mathrm{~cm}$ x $16 \mathrm{~cm}$ ) filled with Harlan Aspen Sani-Chip (7090A) wood bedding (approximately $5 \mathrm{~cm}$ deep) located inside of sound-attenuating chambers. A grid of 25 clear glass marbles was laid gently across the top of the bedding. Each mouse was placed individually into a box and allowed to freely explore for $20 \mathrm{~min}$. At the end of the test, each mouse was quickly and carefully removed and the number of unburied marbles $(\geq 1 / 3$ of the surface showing) was recorded. Marbles were counted by an individual who was trained and reliable with other counters $(\mathrm{r}=.99)$. Locomotor activity was simultaneously recorded for the duration of the test by a camera mounted on the top of the test chamber. The video data were analyzed in real time using ANY-maze (Stoetling, Wool Dale, IL) video tracking software. Dependent variables included total time immobile, total distance traveled and marbles buried. Test boxes were reset between tests.

\section{Experimental Design}

Experiment 1.1: Establish rimonabant-precipitated withdrawal: somatic signs model. In order to establish reliability on somatic signs testing, a study (Schlosburg et al., 2009) was replicated, with minor modifications, to ensure accurate coding of behavior and administration of test. To replicate this study, drug naïve mice ( $\mathrm{n}=8$ per group) were treated repeatedly with THC (50 $\mathrm{mg} / \mathrm{kg}$ ) or vehicle for 5.5 days. On the $6^{\text {th }}$ day, mice were observed according to the somatic signs methods detailed above. I hypothesized that rimonabant-precipitated THC withdrawal would induce a significant increase in head twitches and paw tremors compared to vehicle treated mice. 
Experiment 1.2a: Determine whether a MAGL inhibitor attenuates somatic signs of precipitated

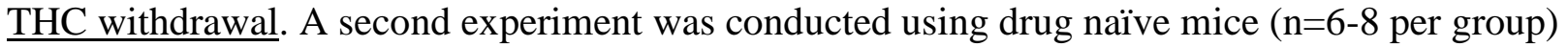
in which the MAGL inhibitor JZL184 (40 mg/kg, i.p.) was administered to test its ability to attenuate any observed somatic signs. I hypothesized that JZL184 would attenuate rimonabant-precipitated THC withdrawal induced head twitches and paw tremors. Although Schlosburg and colleagues (2009) reported that JZL184 significantly attenuates precipitated THC withdrawal, the study was confounded by using a vehicle (PEG200/Tween in a ratio of 4:1) known to cause irritation and decreased locomotor activity. To avoid this confound, we used the milder 1:1:18 vehicle described above.

Experiment 1.2b: Determine whether a MAGL inhibitor attenuates precipitated THC withdrawal in the marble burying test. In order to assess the ability of MAGL inhibition to attenuate withdrawal behavior, JZL184 (40 mg/kg) was administered to drug naïve mice (n=7-8 per group). I hypothesized that JZL184 would attenuate rimonabant-precipitated THC withdrawal determined through an increase in marbles buried.

Experiment 2.1: Develop a novel spontaneous withdrawal model using the marble burying test: Unpublished data from the Kinsey lab indicate that mice subjected to rimonabant-precipitated THC withdrawal bury significantly fewer marbles than controls, in the marble burying test (Trexler et al, in preparation). I hypothesized that spontaneous THC withdrawal would significantly decrease marble burying. To test this hypothesis, mice ( $\mathrm{n}=8-10$ per group) were injected with either THC (50 mg/kg, s.c) or vehicle for 5.5 days. On the $6^{\text {th }}$ day, mice received injections of THC (50 mg/kg) or vehicle (according to randomly assigned group) and were tested in marble burying at several time points $(0,2,4,8,12,24,36$ and $48 \mathrm{~h}$ post injection) per the 
protocol detailed above. These time points are based on a previous report on spontaneous withdrawal from the synthetic CB agonist WIN55,212 in rats (Aceto et al., 2001).

\section{Experiment 2.2: Spontaneous withdrawal in somatic signs. I hypothesized that spontaneous}

THC withdrawal would induce paw tremors and head twitches. To test this hypothesis, drug naïve mice (n=7-8) were injected with either THC (50 mg/kg, s.c) or vehicle for 5.5 days. On the $6^{\text {th }}$ day, mice received injections of THC $(50 \mathrm{mg} / \mathrm{kg}$ ) or vehicle (according to randomly assigned group) and were evaluated in somatic signs testing at several time points $(0,6,12,24$, 36, and 48 $\mathrm{h}$ post injection). Mice tested at 12 and $36 \mathrm{~h}$ post injection had injection schedules offset by $12 \mathrm{~h}$ to allow for testing during the light period of the 12:12 h light/dark cycle (lights on at 6:00 AM). As in Exp 2.1, the time points were chosen based on an established experimental protocol (Aceto et al., 2001). A second hypothesis was that spontaneous THC withdrawal could be attenuated using MAGL inhibitor, JZL184. To evaluate the ability of MAGL inhibition to attenuate symptoms of THC withdrawal, JZL184 (40 mg/kg) or vehicle was administered $2 \mathrm{~h}$ prior to testing at $36 \mathrm{~h}$ (i.e. $34 \mathrm{~h}$ post final THC or vehicle injection).

\section{Statistical analyses}

Data from all studies were analyzed using ANOVA, followed by Bonferroni post hoc tests, with the exception of Experiment 1.1, in which a t-test was used to compare the two groups (THC vs. vehicle). For Experiment 1.2, a 2x2 between subjects ANOVA was used (THC vs. vehicle and JZL184 vs. vehicle). For Experiment 2.1 and 2.2, a mixed design ANOVA was used (THC vs. vehicle as between subjects, ‘time’ as within subjects variable). Inter-rater reliability was assessed using Pearson’s r. Cohen’s kappa was not appropriate because it assumes that the variables are binary. The present variables are continuous, thus Kappa is inappropriate. All data are presented as mean \pm S.E.M. Differences were considered statistically significant if $\mathrm{p}<0.05$. 


\section{Results}

Experiment 1.1: Establish rimonabant-precipitated withdrawal: somatic signs model

Mice were injected with either THC (50 mg/kg, s.c.) or vehicle for 5.5 days. On day 6, the $\mathrm{CB}_{1}$ selective agonist rimonabant (3 mg/kg, i.p.) was administered to precipitate withdrawal, which was evaluated according to the somatic signs detailed above, for occurrences of paw tremors and head twitches. THC treated mice displayed significantly more paw tremors during precipitated withdrawal than vehicle treated mice $[(F(1,14)=44.6$; $<<0.01$; Fig. 3a]. Similarly, head twitches significantly increased in THC treated during precipitated withdrawal compared to vehicle treated mice $[F(1,14)=11.3 ; p<0.01$; Fig. $3 \mathbf{b}]$. These results suggest that THC withdrawal can be evaluated through the observation of somatic signs.

Experiment 1.2a: Attenuate withdrawal with a MAGL inhibitor in somatic signs

Mice were injected with either THC (50 mg/kg) or vehicle for 5.5 days. On day 6, the MAGL inhibitor JZL184 was administered. Rimonabant (3 mg/kg, i.p.) was administered to precipitate withdrawal which was evaluated according to the somatic signs detailed above, for occurrences of paw tremors and head twitches. JZL184 attenuated paw tremors in THC treated mice $[F(3,24)=12.6, p<0.01$; Fig. 4a]. Similarly, JZL184 also attenuated head twitches in THC treated mice $[\mathrm{F}(3,24)=9.1 ; \mathrm{p}<.01$; Fig. 4b]. These data suggest that JZL184 attenuates the somatic symptoms of THC withdrawal, regardless of the vehicle used in the previous study. Experiment 1.2b: Attenuate withdrawal with a MAGL inhibitor in marble burying

Mice were injected with either THC (50 mg/kg, s.c.) or vehicle for 5.5 days. On day 6, the MAGL inhibitor JZL184 (40 mg/kg, i.p.) was administered. Rimonabant (3 mg/kg, i.p.) was administered to precipitate withdrawal which was evaluated according to the marble burying protocol, detailed above, for marbles buried, total distance travelled, and time immobile. JZL184 
did not normalize THC withdrawal related marble burying $[\mathrm{F}(3,27)=10.4$; $\mathrm{p}<0.01$; Fig $5 \mathbf{5 a}$. JZL184 significantly increased time spent immobile $[F(3,26)=9.5 ; \mathrm{p}<0.01$; Fig. $5 \mathbf{b}]$. Total distance travelled was decreased by JZL184 treatment as well $[F(3,24)=9.8, p<0.01$; Fig 5c $]$. Taken together, the decreases seen in vehicle treated mice given JZL184 in immobility and distance suggest that JZL184 at $40 \mathrm{mg} / \mathrm{kg}$ may have a sedative effect (Kinsey et al., 2011). Moreover, JZL184 does not attenuate emotionality-related measures of withdrawal.

Experiment 2.1: Spontaneous withdrawal in marble burying

Mice were injected with either THC (50 mg/kg, s.c.) or vehicle for 5.5 days. On day 6 , mice were injected with either THC or vehicle and were then immediately placed into the marble burying test. Tests were repeated at 2, 4, 8, 12 and $24 \mathrm{~h}$. The first trial revealed a significant decrease in marbles buried for both vehicle and THC treated groups $[\mathrm{F}(1,14)=5.206 ; \mathrm{p}<.05$; Fig. 6a). Post hoc analyses revealed that THC withdrawal decreased marbles buried at $12 \mathrm{~h}$, as compared to the vehicle group. THC had no statistically significant effect on immobility $[F(1,14)=1.813 ; p=.199 ;$ Fig. 6b $]$. Taken together, these results suggest that the differences seen may be a result of a time of day effect, as testing was conducted around the time when lights typically go out for the night.

Given the possible baseline differences between the groups, a second trial was run to attempt replication. The second experiment revealed no effect of THC withdrawal $[\mathrm{F}(1,17)=$ $.015 ; \mathrm{p}=.91$; Fig. 6c $]$ or immobility $[\mathrm{F}(1,17)=.232 ; \mathrm{p}=.64$; Fig. 6d $]$.

Because of the disagreement between the study and replication, a second replication was run. The third trial tested animals at $0,2,4,8,12,24,36$ and $48 \mathrm{~h}$ using two separate groups of mice (one group tested at $0,2,4,8,24$, and $48 \mathrm{~h}$, one group tested at 12 and $36 \mathrm{~h}$ to control for time of day effects). This trial found no differences in marbles buried across time points or 
between treatment groups $[F(1,16)=.017 ; \mathrm{p}=.899$; Fig. 6e $]$. There were also no changes in immobility $[F(1,16)=3.120 ; p=.10$; Fig. 6f $]$. Taken together, these results suggest that marble burying may not be appropriate for evaluating spontaneous withdrawal.

Experiment 2.2: Spontaneous withdrawal in somatic signs

Mice were injected with either THC (50 mg/kg, s.c.) or vehicle for 5.5 days. On day 6 , mice were injected with either THC or vehicle and were then immediately placed into the somatic signs test apparatus. Mice were tested 0, 6, and $24 \mathrm{~h}$ post-injection, with a second group tested at 12 and $36 \mathrm{~h}$, in order to avoid testing during the dark phase of the light/dark cycle. Statistical analyses revealed a significant increase in paw tremors $[F(6,4)=45.950 ; p<.01$; Fig. 7a]. Post hoc analyses revealed that this effect was driven by the 24 and $36 \mathrm{~h}$ observations. THC abstinence also significantly increased head twitches $[F(6,4)=13.950 ; p<.01$; Fig. 7b $]$. Post hoc analysis revealed that this spontaneous THC withdrawal effect was driven by the $36 \mathrm{~h}$ observation.

In an attempt to replicate these results, another experiment was run following the same somatic signs protocol. This experiment also consisted of two groups, with the first group tested at 0, 6, 24 and $48 \mathrm{~h}$ post-injection and the second tested at 12 and $36 \mathrm{~h}$ post-injection. Two hours prior to testing at $36 \mathrm{~h}$, animals were injected with either vehicle or JZL184 (40 mg/kg). Again, increases in paw tremors were seen at $36 \mathrm{~h}$ abstinence for the THC treated mice $[\mathrm{F}(1,9) 18.9$; p<.01; Fig. 7c]. THC treated animals that also received JZL184, however, exhibited significantly fewer paw tremors than THC treated animals that received vehicle $[\mathrm{F}(2,18)=9.208 ; \mathrm{p}<.01$; Fig 8a]. Head twitches significantly increased in THC treated animals at 24 and $36 \mathrm{~h}$ post-injection $[F(1,9)=26.361 ; p=.01 ;$ Fig 7d]. Post hoc analyses revealed that JZL184 pretreatment blocked the THC withdrawal-induced head twitches (Fig. 8b). Taken together, these results indicate that 
spontaneous withdrawal can be observed in mice as evaluated through somatic signs, between 24 and $48 \mathrm{~h}$ following THC injection with a peak at $36 \mathrm{~h}$. Moreover, the behaviors exhibited during THC withdrawal can be attenuated using JZL184.

\section{Discussion}

The current study aimed to evaluate the administration of a MAGL inhibitor, JZL184, as a method of attenuating precipitated withdrawal in a mouse model of drug dependence. The $\mathrm{CB}_{1}$ selective agonist rimonabant significantly reduced marble burying in mice administered THC for 6 days. This rimonabant-precipitated withdrawal had no effect on locomotor activity and was not reversed by administering the eCB enzyme inhibitor JZL184. On the other hand, the somatic signs of rimonabant-precipitated THC withdrawal were reversed by JZL184, as reported previously (Schlosburg et al., 2009). In addition, the study sought to develop a model of spontaneous withdrawal using both traditional somatic signs evaluation and less frequently used emotionality models to identify peak symptom time frames. We found that THC administration, followed by abstinence, significantly increased somatic signs of THC withdrawal, but had no effect on marble burying.

Earlier assertions that JZL184 can effectively attenuate somatic signs of withdrawal (Schlosburg et al., 2009) were supported by the current study. Moreover, the current study expanded on these findings to suggest that the polyethylene glycol vehicle used in the previous study was not responsible for the reductions in paw tremors and head twitches. Of note, the THC withdrawal-induced decrease in marble burying was not reversed by JZL184, which may have had a sedative effect. Earlier studies have also demonstrated sedative effects of JZL184 at high doses (Kinsey et al., 2011). Similarly, although no overt locomotor effect was observed in the somatic signs test, the JZL184-induced normalization of paw tremors and head twitches may also 
be a result of sedation. Thus, future studies will test the efficacy of low-dose JZL184 in reversing THC withdrawal behaviors.

A common critique of cannabinoid withdrawal research is the almost universal use of precipitated withdrawal, because human withdrawal from cannabinoids occurs without the use of a precipitating agent (in this case rimonabant). The present study expanded on spontaneous withdrawal research previously done by Aceto and colleagues (2001) by (1) narrowing the time line of cannabinoid withdrawal to approximately 24 to $48 \mathrm{~h}$; and (2) inducing withdrawal using the commonly used phytocannabinoid, THC, instead of a synthetic cannabinoid. In other words, the present data are the first demonstration of spontaneous THC withdrawal in any preclinical model. The development of a working spontaneous model with specific time points allows for more frequent and targeted use of spontaneous withdrawal. Because mice will habituate to some behavioral assays, the use of the time points developed in this study may allow for the use of additional assays which cannot be done repeatedly.

\section{Limitations}

The present study has several general limitations concerning generality. The findings presented in this study are specific to adult, male C57BL/6J mice. Previous research suggests that withdrawal can vary across sex, age, and strain which indicates that these results may not hold true across all conditions (Damaj, Kao, \& Martin, 2003; Harte-Hargrove \& Dow-Edwards, 2012). There may or may not be differences in drug metabolization between sexes, as earlier studies have noted some sex differences when evaluating withdrawal, however, these effects have not always been withdrawal specific (Marusich, Lefever, Antonazzo, Craft, \& Wiley, 2014). Further limitations are in relation to the design of the present study. Due to the time points chosen, two cohorts of mice had to be used in order to avoid testing during the dark phase of the 
light/dark cycle and, thus, some variance may be due to test day differences. However, the effects of THC treatment were similar at each time point, comparison showed no differences between control groups, and the study did replicate at least once, so a possible cohort difference is unlikely to have a made significant contribution. Another limitation is the route of administration of THC. Subcutaneous injection of THC allows more precise dosing but may also influence the bioavailability of the drug in ways which inhalation may not. Similarly, the current study evaluated only THC withdrawal, and the results cannot necessarily be generalized to other cannabinoids or species, which may have different withdrawal time-courses and profiles. For example, cannabis contains hundreds of compounds, including many cannabinoids, which may interact and be metabolized differently across species.

\section{Future directions}

Several of the limitations previously presented can be addressed in future studies by slightly changing the experimental design. For example, sex, strain, and age differences can be addressed by adjusting the characteristics of the mice used. For example, although most published studies have not observed large effects of sex on cannabinoid withdrawal (Marusich et al., 2014), the novel withdrawal paradigms presented here may be useful for evaluating any possible sex differences. Similarly, future studies will compare the timelines related to other specific cannabinoids and routes of administration, such as the synthetic cannabinoid JWH-018 and cannabis inhalation. Moreover, differences in $\mathrm{CB}_{1}$ receptor density or activity may explain the observed differences between precipitated and spontaneous withdrawal models.

\section{Conclusion}

The results of the present study indicate that the cannabinoid enzyme MAGL is a possible a target compound for attenuating the symptoms of THC withdrawal. It should be noted, 
however, that there may be sedative effects associated with high doses of the MAGL inhibitor JZL184. Further, we report for the first time that rodent models of spontaneous withdrawal may be useful in eliminating the use of precipitating agents and, thus, eliminating a common critique of cannabinoid withdrawal studies. 


\section{References}

Aceto, M. D., Scates, S. M., Lowe, J. A., \& Martin, B. R. (1995). Acknowledgments, 282, 1-2.

Aceto, M., Scates, S., \& Martin, B. (2001). Spontaneous and precipitated withdrawal with a synthetic cannabinoid, WIN 55212-2. European Journal of Pharmacology, 416, 75-81. http://doi.org/10.1016/S0014-2999(01)00873-1

Allsop, D. J., Lintzeris, N., Copeland, J., Dunlop, A., \& McGregor, I. S. (2015). Cannabinoid Replacement Therapy (CRT): Nabiximols (Sativex) as a novel treatment for cannabis withdrawal. Clin Pharmacol Ther, 97(6), 571-574. http://doi.org/10.1002/cpt.109

Anthony, J. C., Warner, L. A., \& Kessler, R. C. (1994). Comparative epidemiology of dependence on tobacco, alcohol, controlled substances, and inhalants: Basic findings from the National Comorbidity Survey. Experimental and Clinical Psychopharmacology, 2(3), 244-268. http://doi.org/10.1037/1064-1297.2.3.244

Atwood, B. K., Lee, D., Straiker, A., Widlanski, T. S., \& Mackie, K. (2011). CP47,497-C8 and JWH073, commonly found in "Spice” herbal blends, are potent and efficacious CB(1) cannabinoid receptor agonists. Eur J Pharmacol, 659(2-3), 139-145. http://doi.org/10.1016/j.ejphar.2011.01.066

Blankman, J. L., Simon, G. M., \& Cravatt, B. F. (2007). A Comprehensive Profile of Brain Enzymes that Hydrolyze the Endocannabinoid 2-Arachidonoylglycerol. Chemistry \& Biology, 14(12), 1347-1356. http://doi.org/10.1016/j.chembiol.2007.11.006

Brents, L. K., Zimmerman, S. M., Saffell, A. R., Prather, P. L., \& Fantegrossi, W. E. (2013). Differential drug-drug interactions of the synthetic Cannabinoids JWH-018 and JWH-073: implications for drug abuse liability and pain therapy. J Pharmacol Exp Ther, 346(3), 350- 
361. http://doi.org/10.1124/jpet.113.206003

Center for Behavioral Health Statistics and Quality. (2015). Behavioral health trends in the United States: Results from the 2014 National Survey on Drug Use and Health, 64. Retrieved from http://www.samhsa.gov/data/sites/default/files/NSDUH-FRR12014/NSDUH-FRR1-2014.pdflnhttp://www.samhsa.gov/data/

Chait, L. D., \& Burke, K. A. (1994). Preference for High- Versus Low-Potency Marijuana. Pharmacology Biochemistry and Behavior, 49(3), 643-647.

Cooper, Z. D., \& Haney, M. (2009). NIH Public Access. New York, 21(2), 104-112. http://doi.org/10.1080/09540260902782752.Actions

Damaj, M. I., Kao, W., \& Martin, B. R. (2003). Characterization of spontaneous and precipitated nicotine withdrawal in the mouse. The Journal of Pharmacology and Experimental Therapeutics, 307(2), 526-534. http://doi.org/10.1124/jpet.103.054908\njpet.103.054908 [pii]

Every-Palmer, S. (2011). Synthetic cannabinoid JWH-018 and psychosis: An explorative study. Drug and Alcohol Dependence, 117(2-3), 152-157. http://doi.org/10.1016/j.drugalcdep.2011.01.012

Falenski, K. W., Thorpe, A. J., Schlosburg, J. E., Cravatt, B. F., Abdullah, R. A., Smith, T. H., ... Sim-Selley, L. J. (2010). FAAH-/- Mice Display Differential Tolerance, Dependence, and Cannabinoid Receptor Adaptation After $\Delta 9$-Tetrahydrocannabinol and Anandamide Administration. Neuropsychopharmacology, 35(8), 1775-1787. http://doi.org/10.1038/npp.2010.44

Fisar, Z. (2009). Phytocannabinoids and endocannabinoids. Current Drug Abuse Reviews, 
2(October), 51-75. http://doi.org/10.2174/1874473710902010051

Freeman, T. P., \& Winstock, A. R. (2015). Examining the pro fi le of high-potency cannabis and its association with severity of cannabis dependence. Psychological Medicine, 45, 31813189. http://doi.org/10.1017/S0033291715001178

Gaoni, Y., \& Mechoulam, R. (1964). Isolation, structure, and partial synthesis of an active constituent of hashish. Journal of the American Chemical ..., 86, 1646-1647. http://doi.org/10.1021/ja01062a046

Harte-Hargrove, L. C., \& Dow-Edwards, D. L. (2012). Withdrawal from THC during adolescence: sex differences in locomotor activity and anxiety. Behav Brain Res, 231(1), 48-59. http://doi.org/S0166-4328(12)00177-5 [pii]ır10.1016/j.bbr.2012.02.048 [doi]

Hermanns-Clausen, M., Kneisel, S., Szabo, B., \& Auwärter, V. (2013). Acute toxicity due to the confirmed consumption of synthetic cannabinoids: clinical and laboratory findings. Addiction, 108(3), 534-544. http://doi.org/10.1111/j.1360-0443.2012.04078.x

Hout, M. C. Van, \& Hearne, E. (2016). User Experiences of Development of Dependence on the Synthetic Cannabinoids , 5f-AKB48 and 5F-PB-22, and Subsequent Withdrawal Syndromes. Int J Ment Health Addiction. http://doi.org/10.1007/s11469-016-9650-x

Kinsey, S. G., O’Neal, S. T., Long, J. Z., Cravatt, B. F., \& Lichtman, A. H. (2011). Inhibition of endocannabinoid catabolic enzymes elicits anxiolytic-like effects in the marble burying assay. Pharmacology Biochemistry and Behavior, 98(1), 21-27. http://doi.org/10.1016/j.pbb.2010.12.002

Lichtman, A. H., Fisher, J., \& Martin, B. R. (2001). Precipitated cannabinoid withdrawal is reversed by Delta(9)-tetrahydrocannabinol or clonidine. Pharmacology, Biochemistry, and 
Behavior, 69(1-2), 181-8. http://doi.org/S0091-3057(01)00514-7 [pii]

Lombard, C., Nagarkatti, M., \& Nagarkatti, P. (2007). CB2 cannabinoid receptor agonist, JWH015, triggers apoptosis in immune cells: Potential role for CB2-selective ligands as immunosuppressive agents. Clinical Immunology, 122(3), 259-270. http://doi.org/10.1016/j.clim.2006.11.002

Marusich, J. A., Lefever, T. W., Antonazzo, K. R., Craft, R. M., \& Wiley, J. L. (2014). Evaluation of sex differences in cannabinoid dependence. Drug and Alcohol Dependence, 137, 20-28. http://doi.org/10.1016/j.drugalcdep.2014.01.019

McQuade, D., Hudson, S., Dargan, P. I., \& Wood, D. M. (2013). First European case of convulsions related to analytically confirmed use of the synthetic cannabinoid receptor agonist AM-2201. Eur J Clin Pharmacol, 69(3), 373-376. http://doi.org/10.1007/s00228$012-1379-2$

Mechoulam, R., \& Parker, L. a. (2012). The Endocannabinoid System and the Brain. Annual Review of Psychology, 64(1), 120717165617008. http://doi.org/10.1146/annurev-psych$113011-143739$

Morgan, C. J. a, Schafer, G., Freeman, T. P., \& Curran, H. V. (2010). Impact of cannabidiol on the acute memory and psychotomimetic effects of smoked cannabis: Naturalistic study. British Journal of Psychiatry, 197(4), 285-290. http://doi.org/10.1192/bjp.bp.110.077503

Pertwee, R. G. (2009). Emerging strategies for exploiting cannabinoid receptor agonists as medicines. British Journal of Pharmacology, 156(3), 397-411. http://doi.org/10.1111/j.1476-5381.2008.00048.x

Piomelli, D., Haney, M., Budney, A. J., \& Piazza, P. V. (2016). Legal or Illegal , Cannabis Is 
Still Addictive. Cannabis and Cannabinoid Research, 1(1), 47-53.

http://doi.org/10.1089/can.2015.29004.rtd

Rajasekaran, M., Brents, L. K., Franks, L. N., Moran, J. H., \& Prather, P. L. (2013). Human metabolites of synthetic cannabinoids JWH-018 and JWH-073 bind with high affinity and act as potent agonists at cannabinoid type-2 receptors. Toxicol Appl Pharmacol, 269(2), 100-108. http://doi.org/10.1016/j.taap.2013.03.012

Ramesh, D., \& Haney, M. (2015). Textbook of Addiction Treatment: International Perspectives. Textbook of Addiciont Treatment: Internacional Prespectives, 367-380. http://doi.org/10.1007/978-88-470-5322-9

Regard, J. B., Sato, I. T., \& Coughlin, S. R. (2009). NIH Public Access. October, 135(3), 561571. http://doi.org/10.1016/j.cell.2008.08.040.Anatomical

Schlosburg, J. E., Carlson, B. L. a, Ramesh, D., Abdullah, R. a, Long, J. Z., Cravatt, B. F., \& Lichtman, A. H. (2009). Inhibitors of endocannabinoid-metabolizing enzymes reduce precipitated withdrawal responses in THC-dependent mice. The AAPS Journal, 11(2), 342352. http://doi.org/10.1208/s12248-009-9110-7

Sherman, B. J., \& McRae-Clark, A. L. (2016). Treatment of Cannabis Use Disorder: Current Science and Future Outlook. Pharmacotherapy: The Journal of Human Pharmacology and Drug Therapy. http://doi.org/10.1002/phar.1747

Singh, U. P., Singh, N. P., Singh, B., Price, R. L., Nagarkatti, M., \& Nagarkatti, P. S. (2012). Cannabinoid receptor-2 (CB2) agonist ameliorates colitis in IL-10 -/- mice by attenuating the activation of $\mathrm{T}$ cells and promoting their apoptosis. Toxicology and Applied Pharmacology, 258(2), 256-267. http://doi.org/10.1016/j.taap.2011.11.005 
Thomas, A., Burant, A., Bui, N., Graham, D., Yuva-Paylor, L. A., \& Paylor, R. (2009). Marble burying reflects a repetitive and perseverative behavior more than novelty-induced anxiety. Psychopharmacology, 204(2), 361-373. http://doi.org/10.1007/s00213-009-1466-y

Zimmermann, U. S., Winkelmann, P. R., Pilhatsch, M., Nees, J. A., Spanagel, R., \& Schulz, K. (2009). Withdrawal Phenomena and Dependence Syndrome After the Consumption of “Spice Gold.” Dtsch Arztebl International, 106(27), 464-467.

http://doi.org/10.3238/arztebl.2009.0464 
Treatment groups for study

Experiment 1.1

\begin{tabular}{|c|c|}
\hline THC (50mg/kg) & 8 \\
\hline Vehicle & 8 \\
\hline
\end{tabular}

Experiment 1.2

\begin{tabular}{|c|c|}
\hline THC (50mg/kg) + JZL184 & 8 \\
\hline THC (50mg/kg) + Vehicle & 8 \\
\hline Vehicle + JZL184 & 8 \\
\hline Vehicle + Vehicle & 8 \\
\hline
\end{tabular}

Experiment 2.1

\begin{tabular}{|c|c|}
\hline THC & 38 \\
\hline Vehicle & 38 \\
\hline
\end{tabular}

Experiment 2.2

\begin{tabular}{|c|r|}
\hline THC $(50 \mathrm{mg} / \mathrm{kg})$ & 32 \\
Vehicle & 24 \\
\hline
\end{tabular}

Table. Total number of mice used in study. 


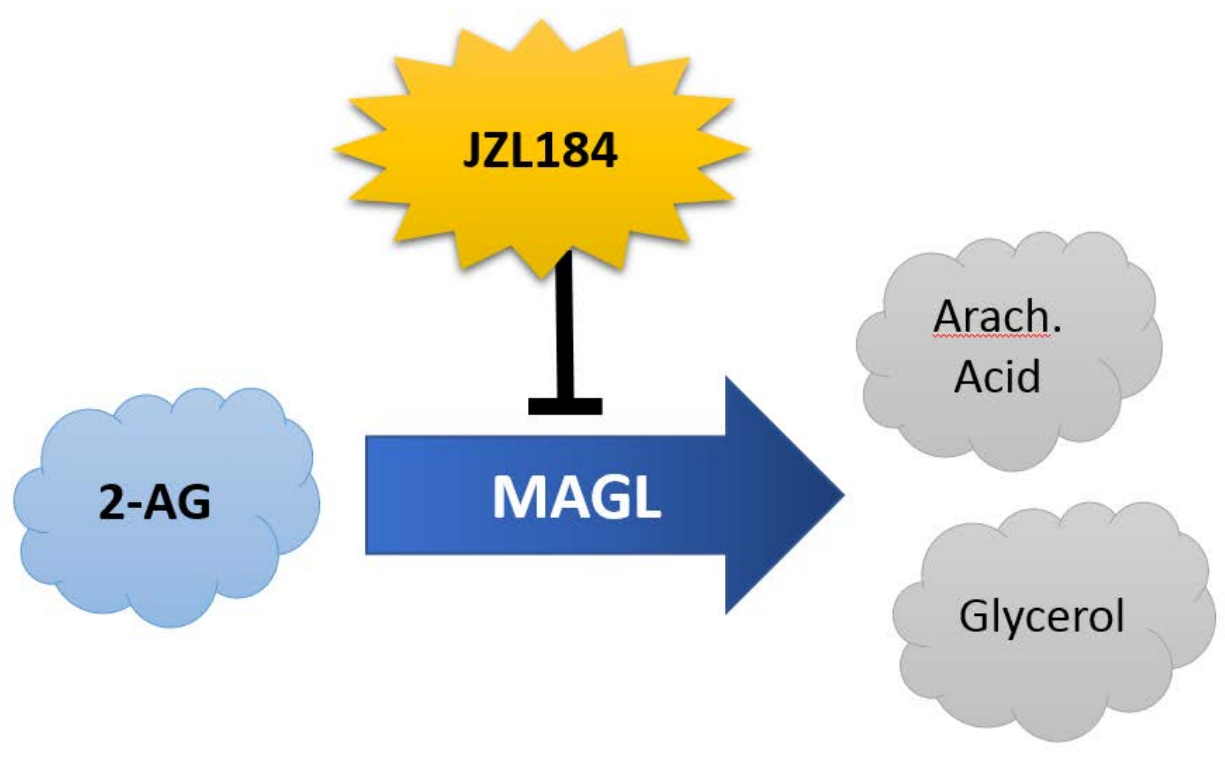

Figure 1. Schematic of endocannabinoid modulation by JZL184. Under normal conditions, the endocannabinoid 2-Arachidonoylglycerol (2-AG) is catabolized by enzyme monoacylglycerol lipase (MAGL) into the metabolites arachidonic acid and glycerol. The synthetic enzyme inhibitor JZL184 selectively inhibits the ability of MAGL to catabolize 2-AG, which leads to increases in tissue levels of 2-AG in live animals. 


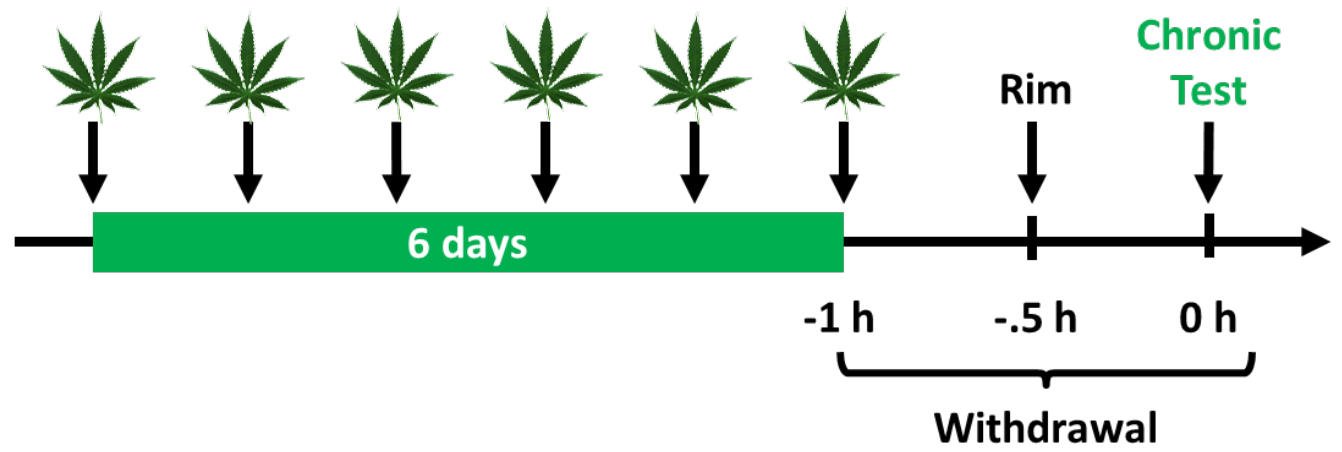

Figure 2. Timeline for proposed rimonabant-induced THC dosing and testing, as in Exp 1. For Experiment 2, rimonabant was not administered (i.e., spontaneous withdrawal), and testing proceeded over the course of many hours after the final administration of THC. 

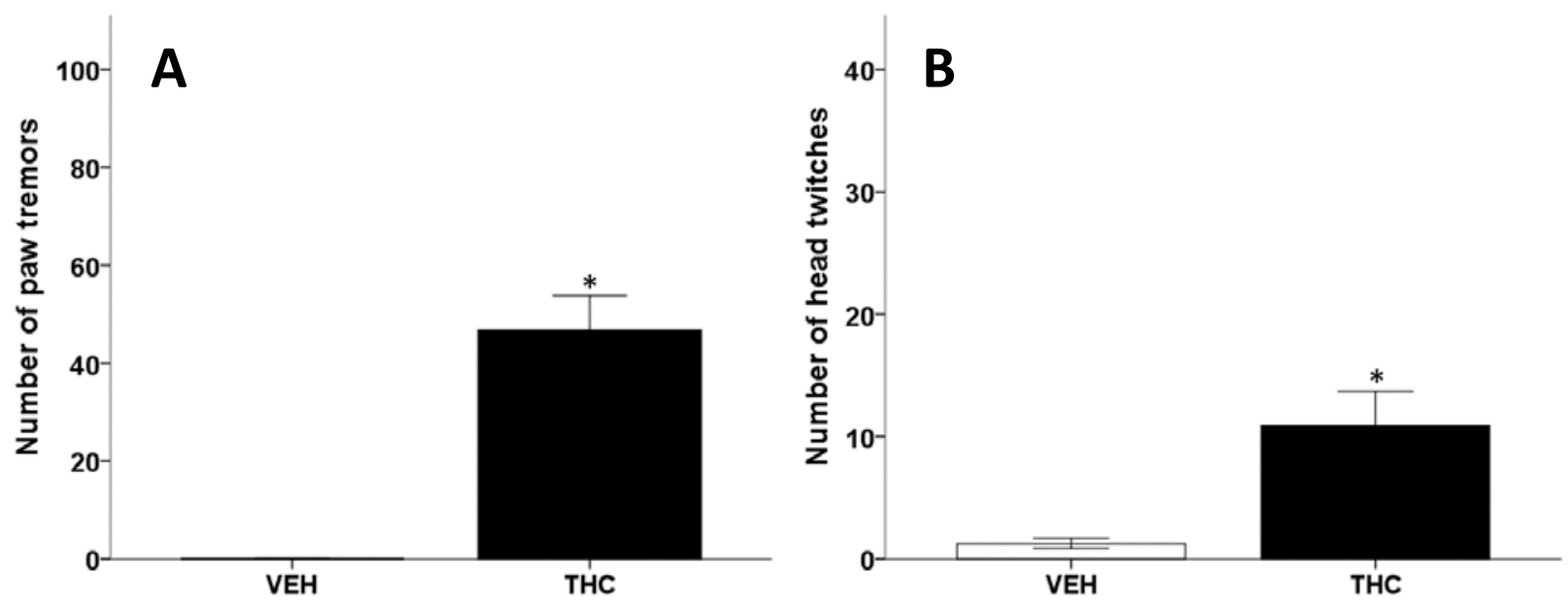

Figure 3. Mice undergoing precipitated THC withdrawal exhibit increased paw tremors (a) and head twitches (b). Mice were injected with either THC (50 mg/kg, s.c.) or vehicle for 6 days, and then withdrawal was precipitated with the $\mathrm{CB}_{1}$ selective antagonist, rimonabant ( $3 \mathrm{mg} / \mathrm{kg}$, i.p.). $\mathrm{n}=8$ per group. $* \mathrm{p}<.05$ versus vehicle control. 

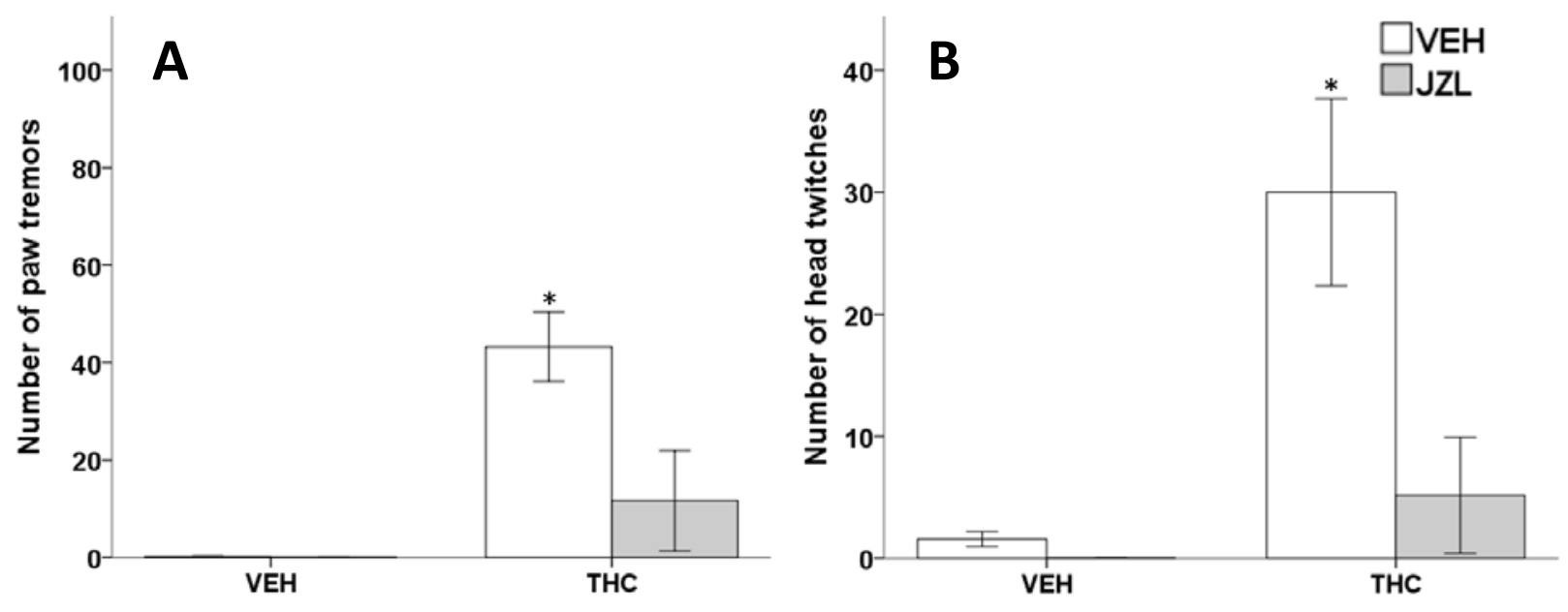

Figure 4. Treatment with JZL (40 mg/kg) decreases (a) paw tremors and (b) head twitches seen during precipitated THC (50 mg/kg) withdrawal. Mice were injected with either THC (50 mg/kg, s.c.) or vehicle for 6 days, and then withdrawal was precipitated with the $\mathrm{CB}_{1}$ selective antagonist, rimonabant ( $3 \mathrm{mg} / \mathrm{kg}$, i.p.). Prior to rimonabant injection, mice were treated with either JZL184 (40 mg/kg, i.p.) or vehicle. $\mathrm{n}=6$-8 per group. ${ }^{*} \mathrm{p}<.05$ versus vehicle control. 


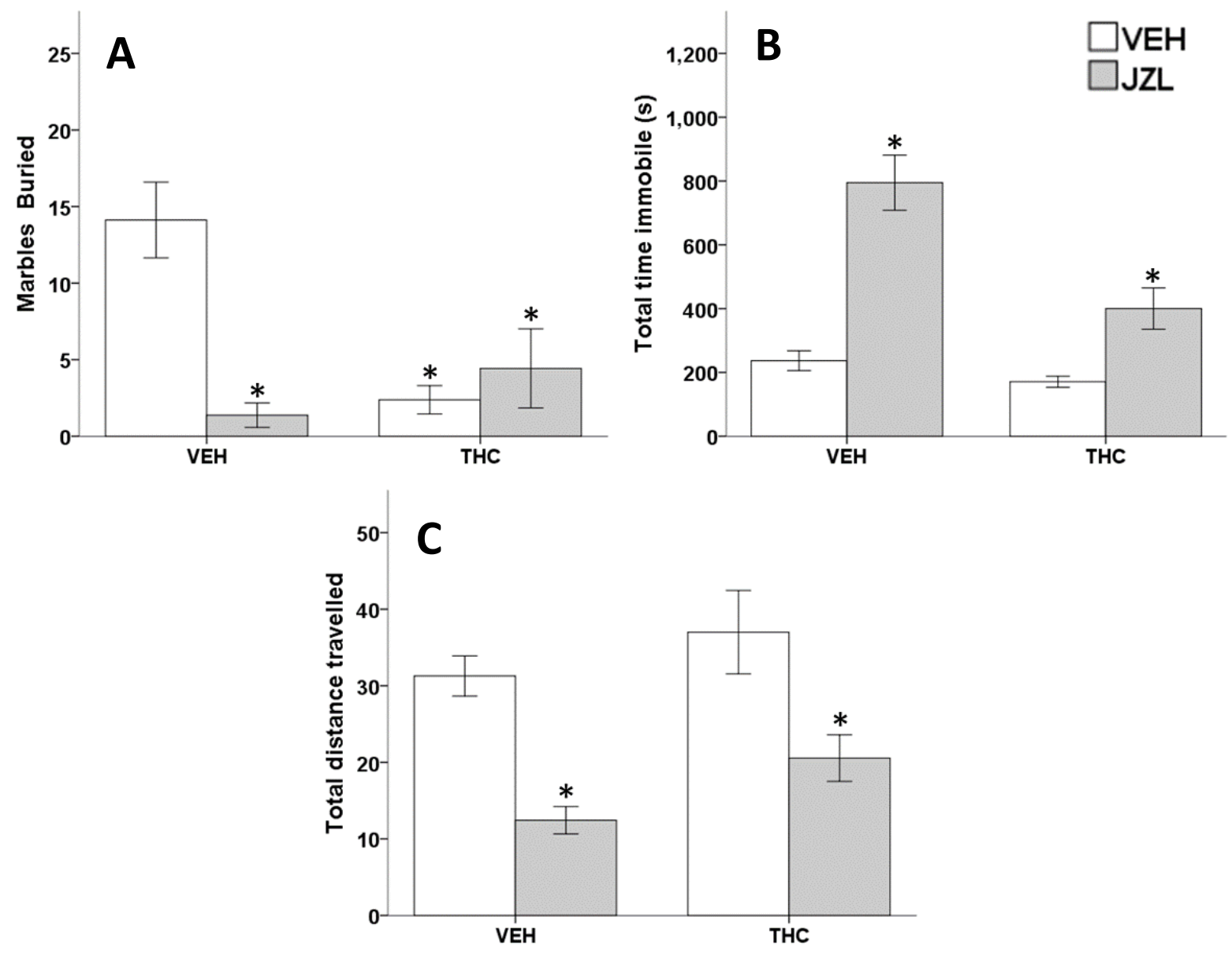

Figure 5. In THC-dependent mice, treatment with JZL184 (40 mg/kg) prior to rimonabant (a) did not attenuate altered marble burying and (b) increased time spent immobile. JZL184 caused (c) decreased total distance travelled during precipitated THC (50 mg/kg) withdrawal. n= 7-8 per group. ${ }^{*} \mathrm{p}<.05$ versus vehicle/vehicle, $\# \mathrm{p}<.05$ versus vehicle treated group. 

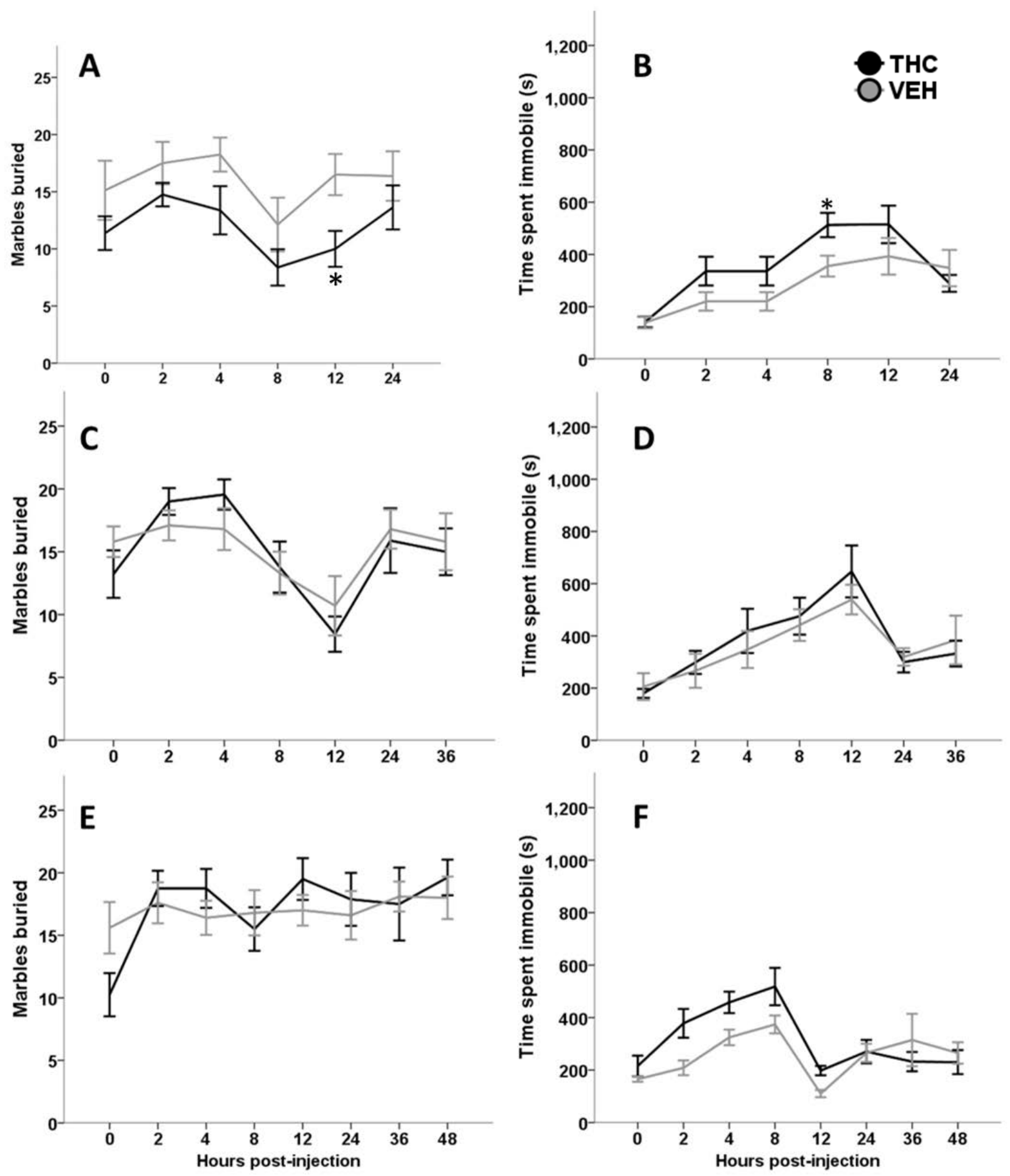

Figure 6. Three trials examining spontaneous THC withdrawal found no effects in the marble burying test. The first attempt to demonstrate spontaneous THC (50 mg/kg) withdrawal showed a significant (a) increase in marbles buried at $12 \mathrm{~h}$ and (b) increase in immobility at $8 \mathrm{~h}$.

Subsequent attempts to replicate these results demonstrated: (c) a decrease in marbles buried at $12 \mathrm{~h}$ for both vehicle and THC treated mice, (d) no change in immobility across treatment and time points, (e) no change in marbles buried or (f) immobility across time points and treatment. $\mathrm{n}=8$-10 per group. ${ }^{*} \mathrm{p}<.05$ versus vehicle control. 

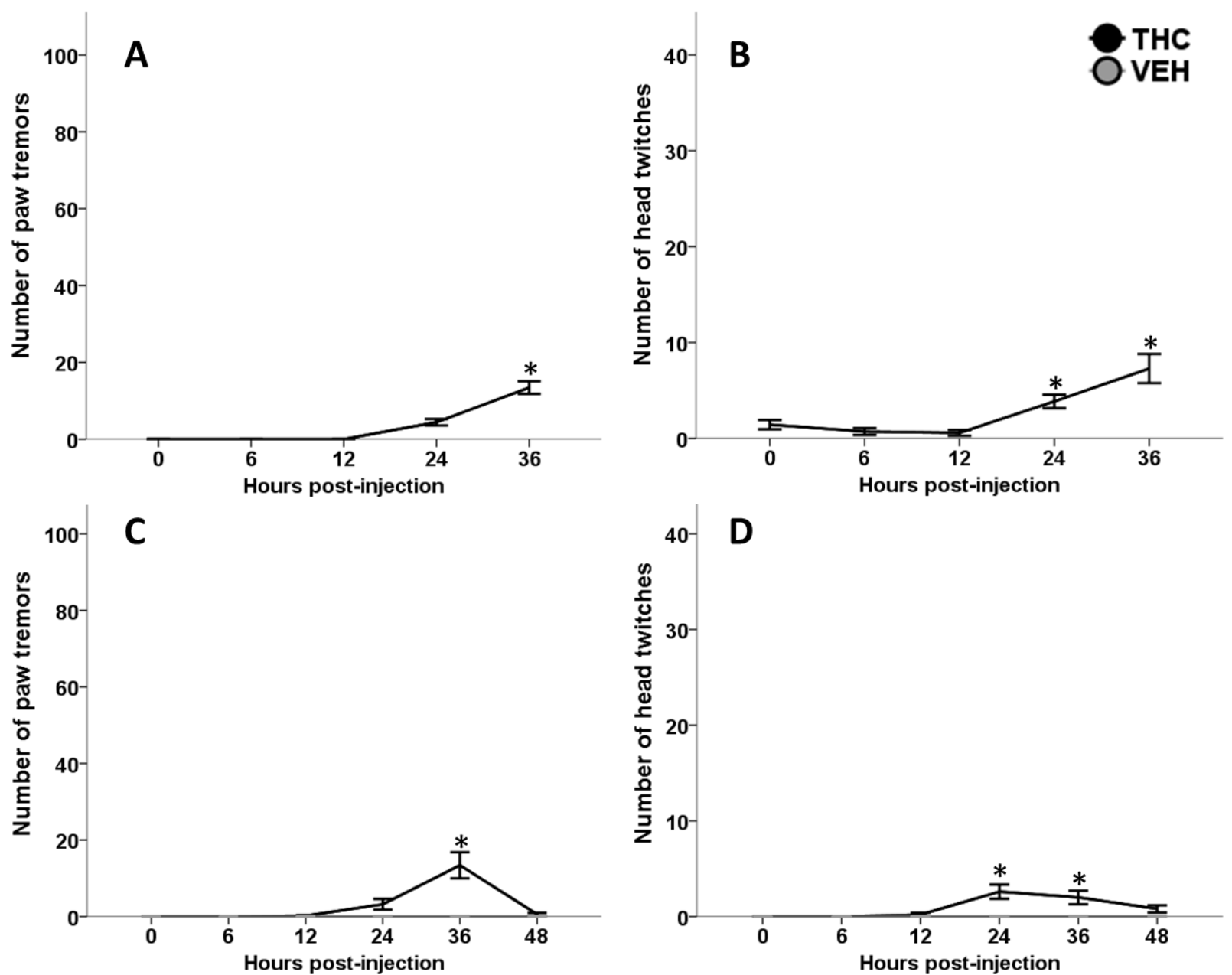

Figure 7. Mice show somatic signs of THC withdrawal 24-36 hours after abstinence. During spontaneous THC (50 mg/kg) withdrawal, mice exhibited increased (a) paw tremors at 24 and 36 $\mathrm{h}$ and (b) increased head twitches at $36 \mathrm{~h}$. An attempt to replicate demonstrated (c) increased paw tremors at $36 \mathrm{~h}$ and $(\mathbf{d})$ increased head twitches at 24 and $36 \mathrm{~h} . \mathrm{n}=7-8$ per group. ${ }^{*} \mathrm{p}<.05$ versus vehicle control. 

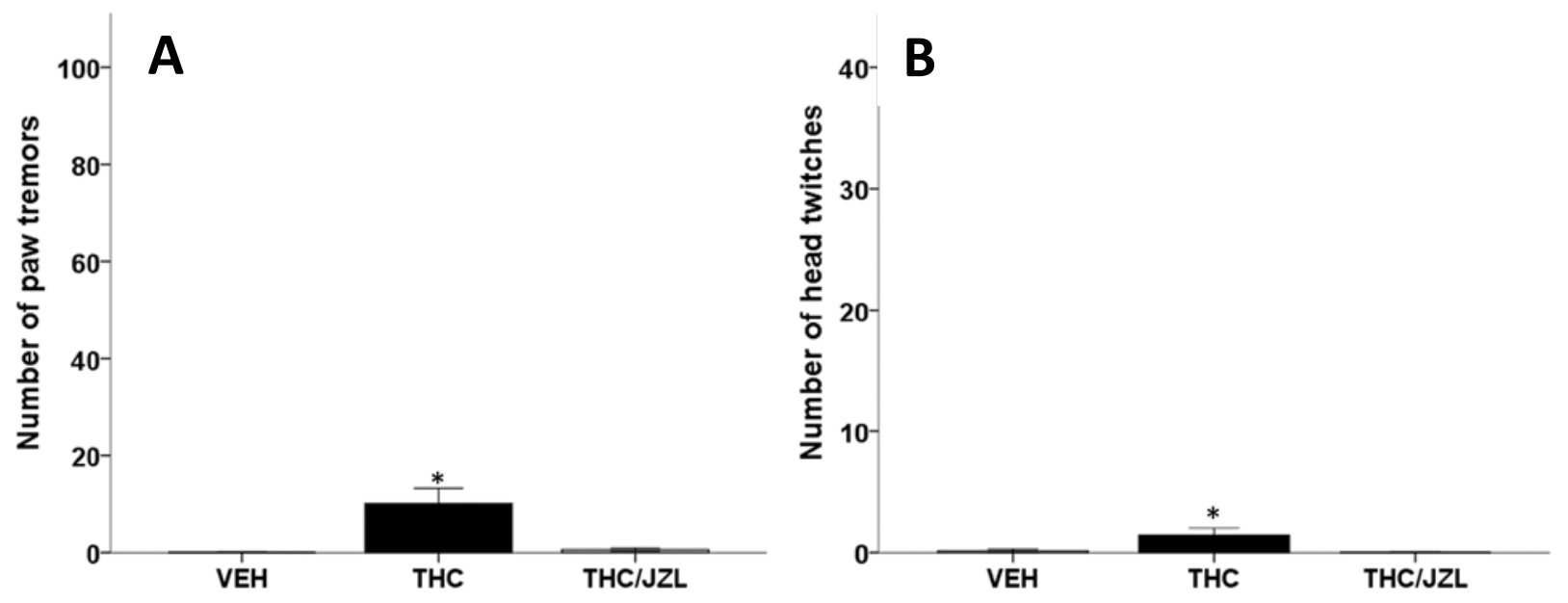

Figure 8. Mice tested at $36 \mathrm{~h}$ during spontaneous THC (50 mg/kg) withdrawal exhibited increased (a) paw tremors, however mice treated with JZL184 showed significantly fewer paw tremors. Similarly, mice treated with THC $(50 \mathrm{mg} / \mathrm{kg})$ showed increased (b) head twitches while mice treated with JZL184 showed significantly fewer head twitches. $n=7-8$ per group.* $p<.05$ versus vehicle control. 